\title{
Global Wesleyan Encyclopedia of Biblical Theology
}

Robert D. Branson, ed. Global Wesleyan Encyclopedia of Biblical Theology. Kansas City: The Foundry Publishing, 2020. 463 pp. \$55.99. Hardcover. ISBN: 9780834138230.

The Global Wesleyan Encyclopedia of Biblical Theology is a companion piece to the Global Wesleyan Dictionary of Theology, which The Foundry Publishing (then Beacon Hill Press) published in 2013. The volume opens with a "Preface and Purpose" section (7), followed by brief instructions on how to use the anthology (9), a list of contributors and their entries (11-24), a list of articles arranged by category (25-7), a table of abbreviations (29-33), and an introduction to the "Wesleyan hermeneutical tradition" (35-7). From there, the work consists of encyclopedia articles and concludes with a scripture index that includes both page numbers and article references (431-63). The articles vary in length, structure, and scope. Although their reading levels also vary, the entries would be accessible for most upper-level college and master's students, as well as theologically-informed laity.

The "Preface and Purpose" section establishes the volume's fourfold purpose: "(1) to define major biblical terms, themes, and concepts and, where appropriate, to offer a characteristic Wesleyan assessment of each; (2) to reflect the global character of Christian faith by the choice of topics to be defined and by the global character of its contributors; (3) to offer when appropriate a theological assessment of the themes and concepts studied; and (4) to provide a guide for understanding the richness of the Wesleyan approach to interpreting Scripture and how it can help Christians in that tradition live and articulate their faith in a global context” (8). In the following I review the collection according to these four aims.

First, this volume successfully introduces a range of "major terms, themes, and concepts" that fall under twelve major headings: "Bible, General;" "Bible, New Testament;" "Bible, Old Testament;" "Church and Culture;" "Hermeneutics;” "Human Qualities;” "Jesus;” "Religious Activities;” "Sacred;" "Theology;" "Theology of Books or Epistles;" and "Word Studies.” It is unclear, however, what criteria the editors used to evaluate what "major" topics to include. For example, under the "Theology of Books or Epistles" category, one finds significant gaps. Although it includes "Deuteronomistic Theology," "Isaiah," "Jeremiah," and "Torah (Law, Instruction)," it contains no entries on the theologies of other Old Testament writings. With all four Gospels and Acts, as well as Paul, Hebrews, and 1-2 Peter represented, theologies of New Testament writings get more attention. Readers may be confused to find chapters on these writings but not others, and with no explanation.

Along these lines, some articles could draw more heavily on recent developments in biblical studies. For example, the article "Grace" does not include important insights from John M. G. Barclay's landmark Paul and the Gift (Grand Rapids, MI: Eerdmans, 2015). Likewise, the entry "Kingdom of God/Heaven” overlooks Jonathan T. Pennington's important Heaven and Earth in the Gospel of Matthew (Leiden: Brill, 2007), which seriously challenges the article's claim that Matthew's Gospel uses "kingdom of heaven" instead of "kingdom of God" because "Judaism commonly used the circumlocution 'heaven' to avoid pronouncing the name of God" (243). Nonetheless, the collection features informative introductory articles on a number of major topics.

Second, with its internationally diverse authors, the anthology nicely displays Christianity's global character. The "Hermeneutics" category especially showcases the work's global representation by including, among others, entries on African, Asian, Caribbean, Indian, and Latin American hermeneutics. On the whole, these pieces offer informative and instructive primers on these in- 
ternational approaches. Yet here the volume could benefit from more consistency and coverage. Concerning consistency, some articles offer seemingly decisive explanations on what constitutes a given hermeneutical approach (e.g., "Biblical Hermeneutics in the African Context" and "Canonical Hermeneutics"), while other entries offer a survey of multiple approaches that fit within that entry (e.g., "Asian Hermeneutics," "Feminist Hermeneutics," and "Indian Hermeneutics"). Regarding coverage, as a volume published in 2020, readers might be disappointed not to find articles related to several issues that are especially pressing for contemporary Wesleyan churches. For instance, it might include models like womanist, post-colonial, or empire criticisms, especially since they are referenced in places (e.g., "Caribbean Hermeneutics" and "Feminist Hermeneutics"). Similarly, readers might search for entries on race and/or ethnicity, sexuality (though see "Marriage"), or disability, none of which are included.

Third, most of these articles are descriptive, but some offer a bit of "theological assessment" of topics discussed. The article "Free Will," for instance, offers an excellent model for how such assessment can be done in a reference work like this. It features multiple perspectives on free will debates, with discussions of strengths and weaknesses for each, and it includes a succinct summary of Wesleyan perspectives on the topic. "Pauline Theology" similarly gives thoughtful assessment of interpretive trends, and "Wesleyan Hermeneutics" offers an evenhanded analysis of Wesleyan biblical interpretation. In sum, although explicit theological assessment appears infrequently, authors who conduct such assessment do so responsibly and instructively.

The extent to which this volume accomplishes its fourth purpose is mixed. To be sure, the articles alone can help "Christians in [a Wesleyan] tradition live and articulate their faith in a global context." Less certain, however, is how well the work as a whole provides "a guide for understanding the richness of the Wesleyan approach to interpreting Scripture.” Put simply, it is unclear what distinguishes this anthology as Wesleyan. Some entries focus specifically on Wesleyan concerns (e.g., "Wesleyan Hermeneutics," "Wesleyan Understandings of Inspiration of Scripture"), and other selections give some attention to how Wesleyans might understand a given topic (e.g., "Grace”). Yet several topics almost demand engagement with Wesleyan history or theological perspectives but make no mention of Wesley or Wesleyan traditions. Such absences are most striking for topics that lie at the heart of Wesleyan Christianity-e.g., "Holiness," "Regeneration," and "Sanctification." Although the volume only claims to give "a characteristic Wesleyan assessment" in places "where appropriate," I was left wondering why such assessment was so seldom deemed to be appropriate. One could, in fact, easily place most of these articles in another standard encyclopedia or dictionary of biblical theology. In sum, these omissions raise the question, "What is distinctively Wesleyan about the Global Wesleyan Encyclopedia of Biblical Theology, other than that its authors are Wesleyan?"

Yet, even with these criticisms in view, the volume largely accomplishes its purposes. It offers helpful introductions to an array of important and relevant topics and provides a sampling of secondary sources for further reading. One could profitably use this as a primary textbook-alongside supplementary resources-for college or seminary classes. Pastors and interested lay readers may also draw on these articles as entry points to the topics discussed.

David Carr, PhD

Assistant Professort of Biblical Studies, Northeastern Seminary Roberts Wesleyan College

Rochester, NY 